\title{
The Microstructural Study of a Damaged Motorcycle Gear Wheel
}

Petra Kováčiková, Andrej Dubec, Jana Kuricová

Faculty of Industrial Technologies in Púchov, Alexander Dubček University of Trenčín. I. Krasku 491/30, 02001

Púchov. Slovakia. E-mail: petra.kovacikova@tnuni.sk

The main aim of this article is study the cause of gear wheel failure. This component has worked in the motorcycle gearbox. During the operation of the transmission, the gear wheel tooth was broken, which made it impossible to continue running this device. The investigation of the damaged area was focused on determining the chemical composition of the inclusions which are present of gear wheel material as well as detecting changes of material contrast in microlocalities close to the defective areas. The method of energy-dispersive spectroscopy and scnanning electron microscopy were chosen for this type of analysis. Furthermore, the micropurity and microstructure of the material were evaluated by methods of optical microscopy and scanning electron microscopy. Using a thermo-emission scanning electron microscope, the microcrack area was evaluated in the mode of secondary electrons and also in the mode of backscattered electrons. In this way, the fracture surface was examined in terms of its micromorphology as well as material contrast.

Keywords: Gear wheel, Fracture surface, Chemical composition, Optical microscopy, Scanning electron microscopy

\section{Introduction}

The transmission of the engine driving torque to the motorcycle wheel takes place from the engine to the clutch and transmission (primary transmission) and from the transmission to the rear wheel (secondary transmission). When longitudinal engines the main shaft gear units are driven directly by the crankshaft or via a gear reducer that can be toothed spur gears or toothed chain. Gears are the optimal connection between the crankshaft and the clutch [1]. In this article, we focus on tooth failure of components that occurred during the normal operation of a motorcycle transmission. The material under investigation from which the gears are commonly made is steel grade 14 STN 41 4221, which is used to make components subjected to high stress. Such medium carbon steels are tempered to high temperatures (up to temperatures below Ac1) after hardening to ensure high toughness while maintaining high strength. The improvement of mechanical properties by quenching and tempering of steel is caused mainly by grain refinement. In order to achieve optimal properties, it is necessary to follow the correct working procedures not only during heat treatment but also during the application of the cementation layer, which ensures high resistance of components in operating conditions. The chemical composition of cemented steel participates in the course of cementation. In the same cementation environment and under the same cementation conditions, the surface of low carbon steel enriches faster than the surface of steel with higher carbon content. Nickel reduces the rate of cementation, while chromium and other carbide-forming elements increase the carbon content on the surface of the cemented layer. Therefore, it is necessary to carry out the cementation process of these steels in a less active environment. In the structure of such heat-treated materials, there is an undesirable fragments configuration of carbide eutectics in rows, resp. carbide linearity, which causes directional anisotropy of physical and mechanical properties [2].

\section{Materials and methods}

The subject of the research is a gear wheel with a base circle diameter of $74.4 \mathrm{~mm}$, a heel circle diameter of $33 \mathrm{~mm}$, and an overall width of $10 \mathrm{~mm}$. The part was made with 4 weight-reduction holes with a diameter of $10 \mathrm{~mm}$ and a length of $27 \mathrm{~mm}$. The inner functional surface of the wheel for the mating surface of the counterpart had a diameter of $25 \mathrm{~mm}$. The fracture area is indicated by the symbol I and is shown in Fig. 1. In order to ensure all the requirements for the quality of the spare part, a prerequisite for high-quality and accurate production is necessary [3]. Due to the production history of this motorcycle, it was difficult to get an original spare part for the transmission. According to the information provided by the manufacturer, steel grade 14 STN 414221 (EN ISO $20 \mathrm{MnCr} 5$ ) was used for the production of the gear wheel. Such steel, intended for high stress, is processed by technologically demanding processes, in which it is necessary to pay attention to maintaining 
the machining speed. If the cutting speed is too high, the cooling effect is lost and the material is exposed to higher thermal stress.

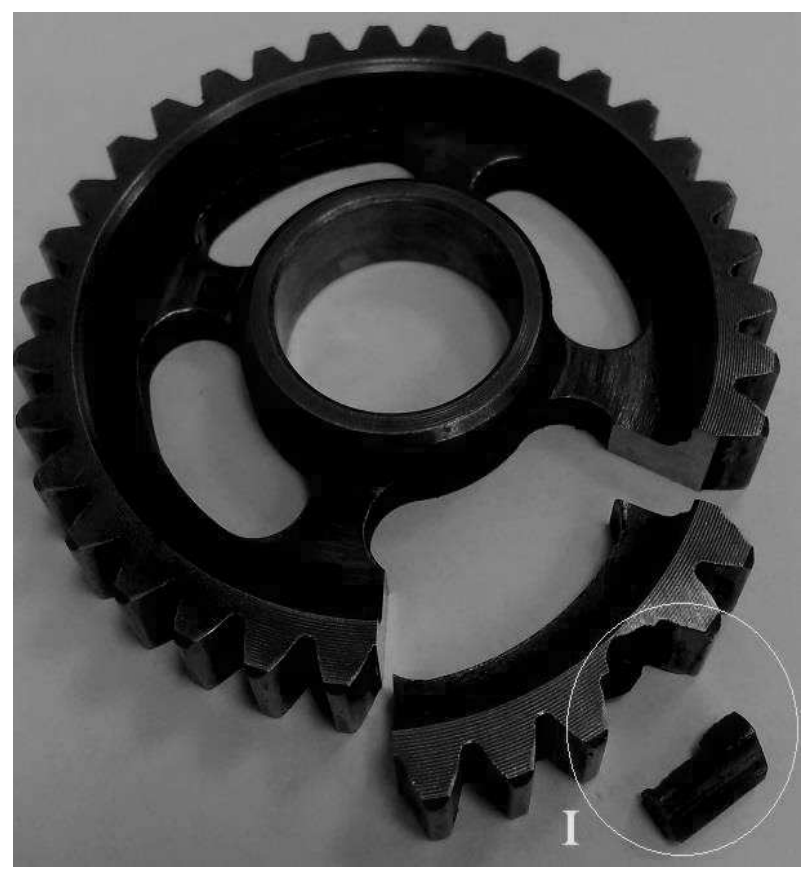

Fig. 1 Marking of the damaged area

Thermal and mechanical stress during grinding affects the residual stress on the surface of the material [4]. The method of optical microscopy was used to gain knowledge about the microstructure of the material. The hardness of the diffusion surface layer is determined by the Vickers microhardness measurement method. The fracture surface of the gear wheel tooth was analyzed by scanning electron microscopy (SEM) using a secondary electron detector for micromorphology evaluation. For the completeness of the information obtained from the fracture surface, the SEM method was supplemented by material contrast analysis in the backscattered electron (BSE) mode. The evaluation of micropurity and the occurrence of inclusions in the material was performed by the SEM method in the BSE mode and supplemented by the analysis of the chemical composition by energy-dispersive spectroscopy.

\section{Results and discussion}

The micropurity of the material core was evaluated on a thermo-emission scanning microscope according to the standard using material contrast analysis concerning the difference in the atomic weight of the metal matrix of the part and the possible occurrence of inclusions. The inclusions location in the form of oxides, and aluminum-based mixed oxides is indicated on Fig. 2 [5].

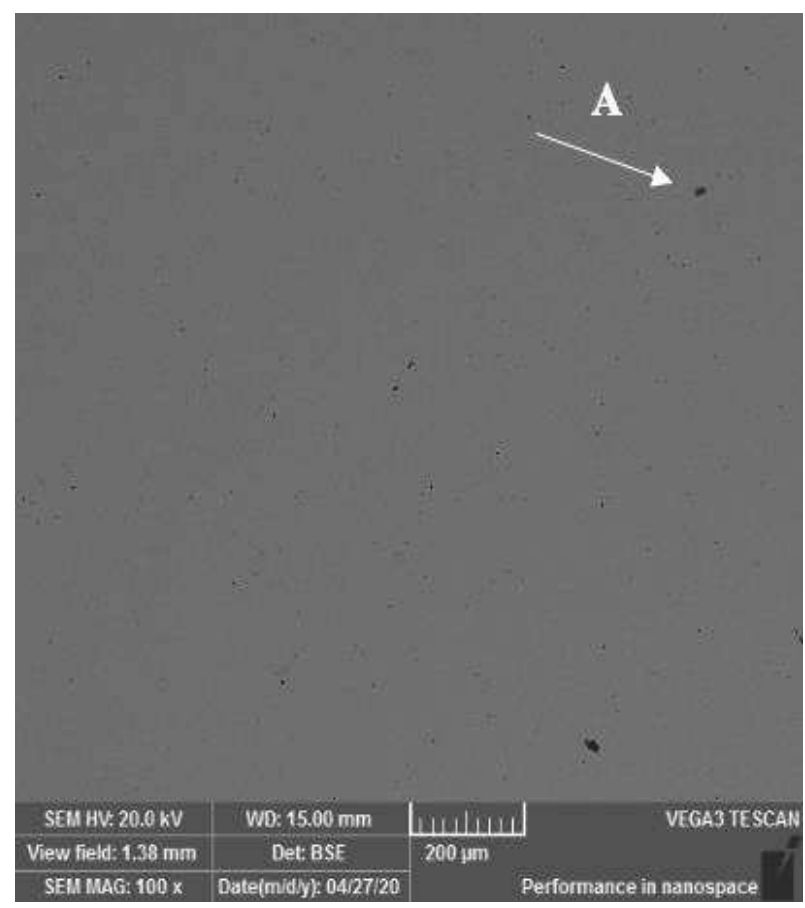

Fig. 2 Location of oxide inclusions

Detailed visualization of this area is visible on the Fig. 3. In this figure we can observe the occurrence of microspace around the inclusions. The chemical base of the inclusions present was confirmed by an EDX detector (Fig. 4, 5).

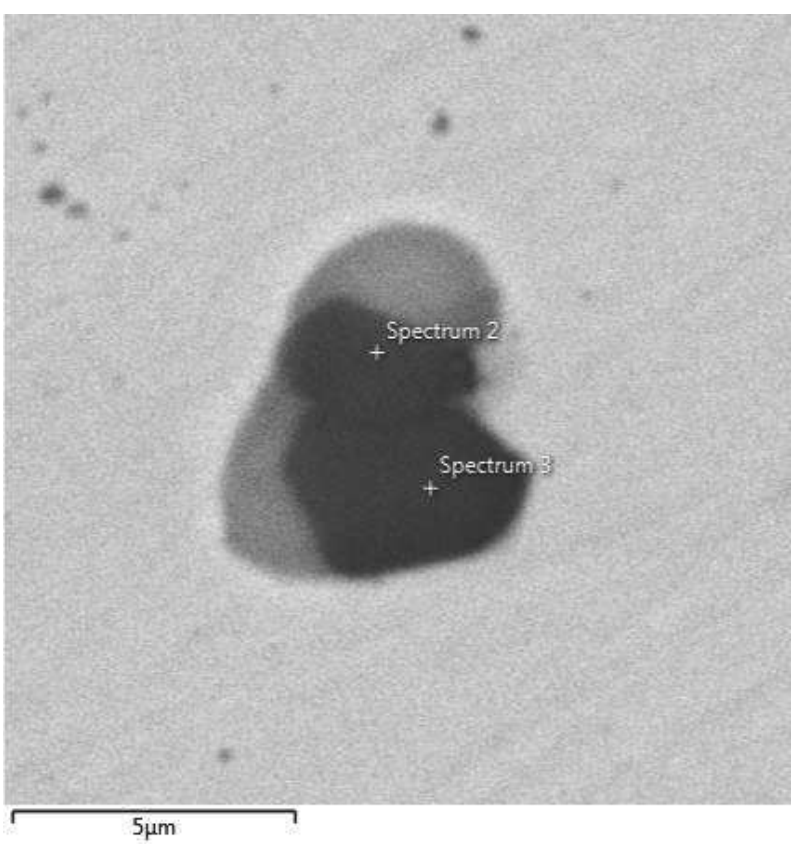

Fig. 3 Detail of oxide inclusions presence from the place A, source area of the EDX detector 


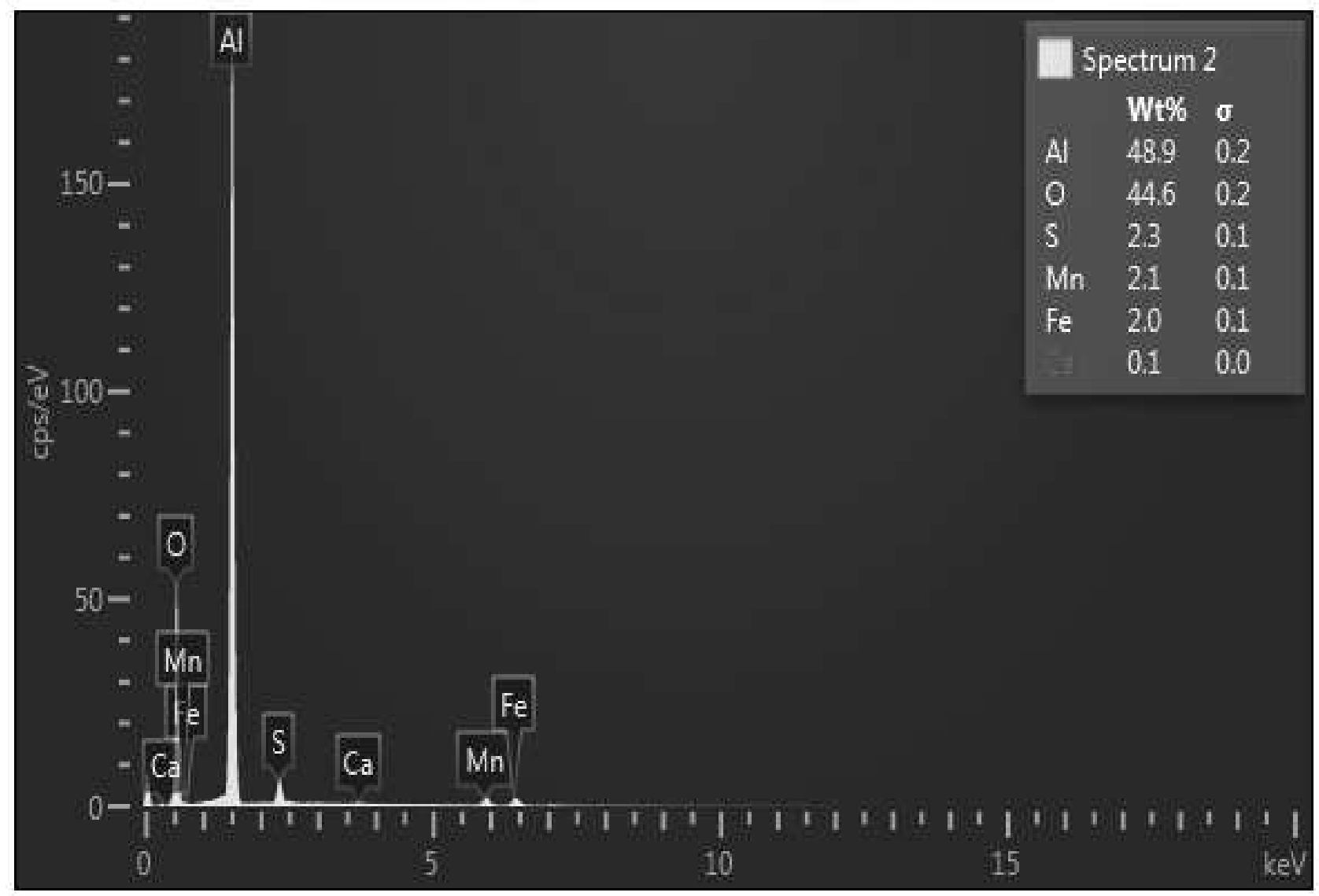

Fig. 4 Chemical spectrum 2 of oxide inclusion

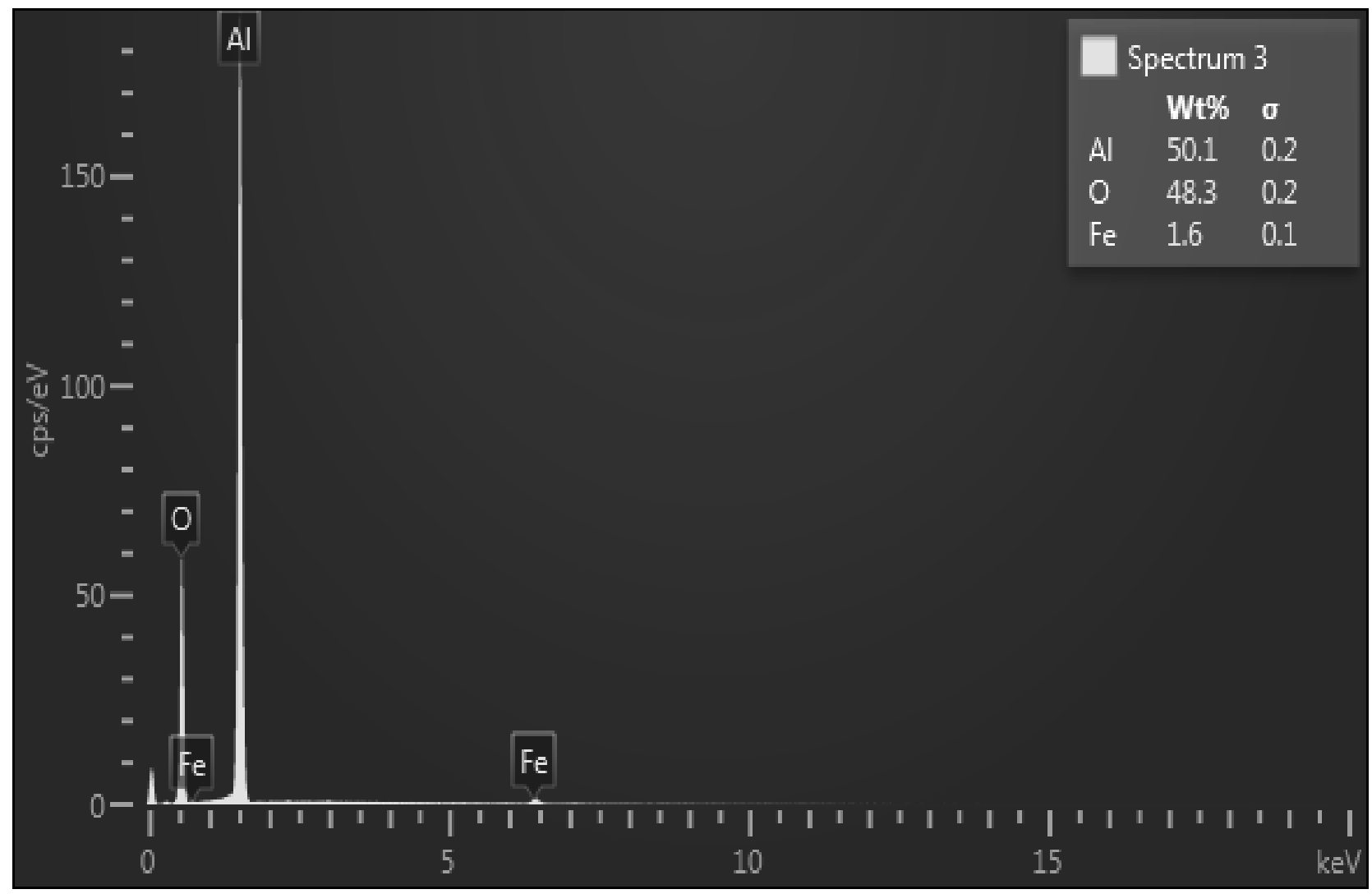

Fig. 5 Chemical spectrum 3 of oxide inclusion 
The inclusions size and distribution corresponding of impurities occurrence up to level 1 according to standard STN 42 0471. In metal matrix were observed MnS inclusions (Fig. 6) with elongated shape. The different ratio in the representation of the basic chemical elements is shown in fig. 7, 8 .

The microstructure of the core was formed by thicker ferritic needles with cementite particles, the presence of carbides were also observed. This microstructure corresponds to the heat treatment after hardening and subsequent high-temperature tempering of martensite up to the upper bainite structure (Fig. 9). The grain size is about $10 \mu \mathrm{m}$. The carbide phase is unevenly distributed in the core of the material, there is a visible indication of the carbides distribution along the grain boundaries and also the presence of precipitates (Fig. 10). Carbides were different in size.

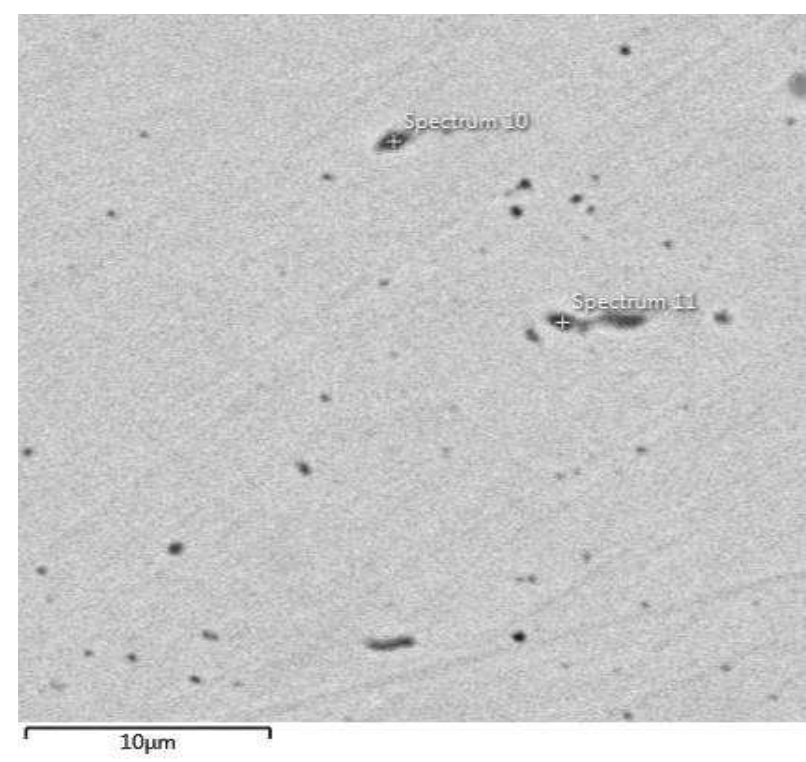

Fig. 6MnS inclusios with elongated shape, source area of the EDX detector

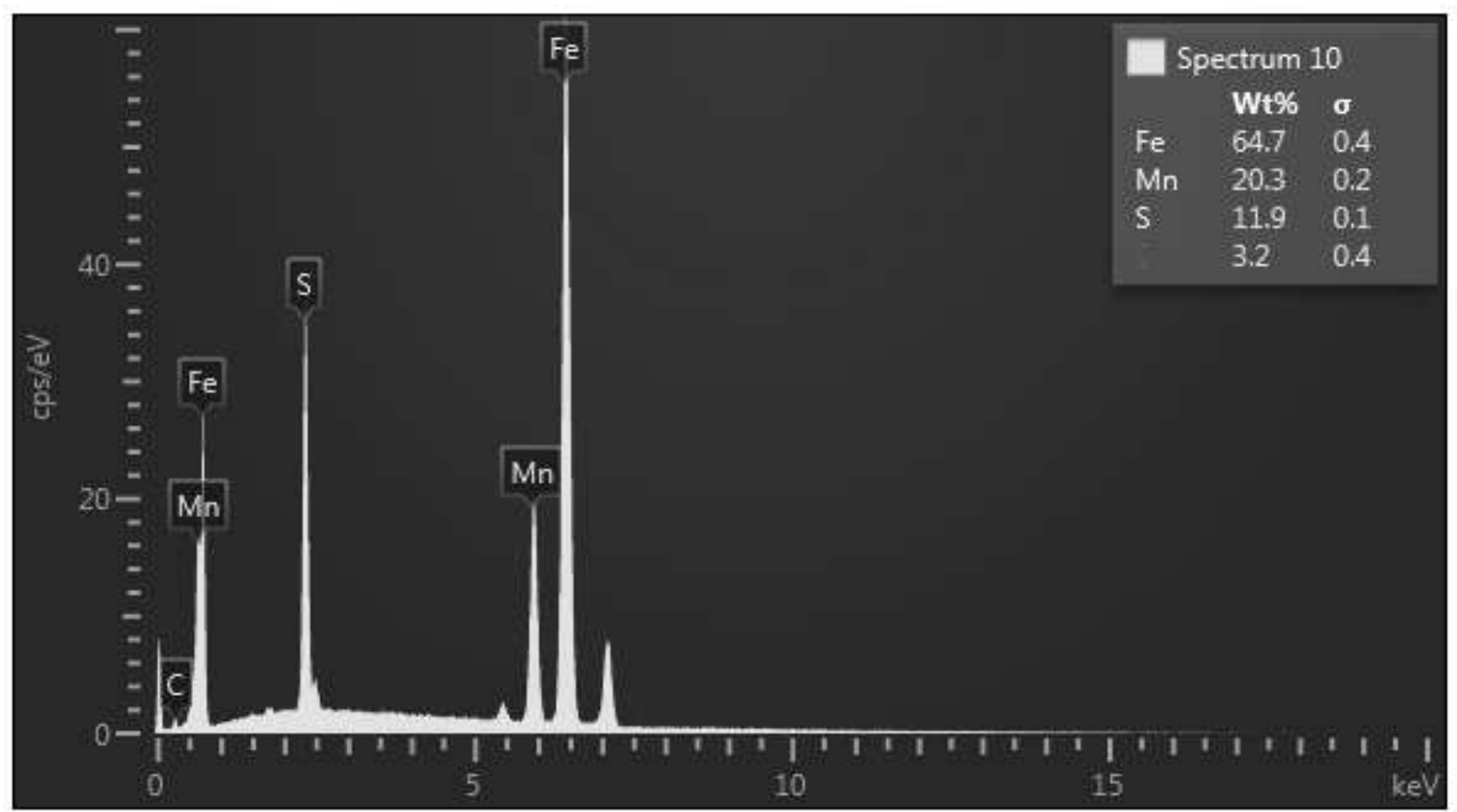

Fig. 7 Chemical spectrum 10 of MnS inclusion

Uneven distribution of the carbide phase along the grain boundaries was visible in the cemented layer. An increased etchant effect was used for visibility of carbides in the microstructure of the cemented layer Nital 2 (Fig 11).

The evaluation of the diffusion surface layer after chemical heat treatment on the gear wheel tooth surface was analyzed by the Vickers hardness measurement method under HV1 loading. For evaluation was used standard ČSN EN ISO 6507-1 Metallic materials - Vickers hardness test - Part 1: Test method. Hardness was measured on the device V10 K/AQ. The cemented layer reached a depth of 437.5 micrometers. The measured values of Vickers's hardness are shown in the table 1 . The hardness measurement process for determining the depth of the cementation layer can be seen in the fig. 12. The measurement of hardness took place from the edge to the core of the material. In all areas marked with the letters A-J, one measurement was performed. Emphasis was placed on adhering to one and a half times the size of individual indentation punctures between adjacent measurements in order not to affect the measurement. 


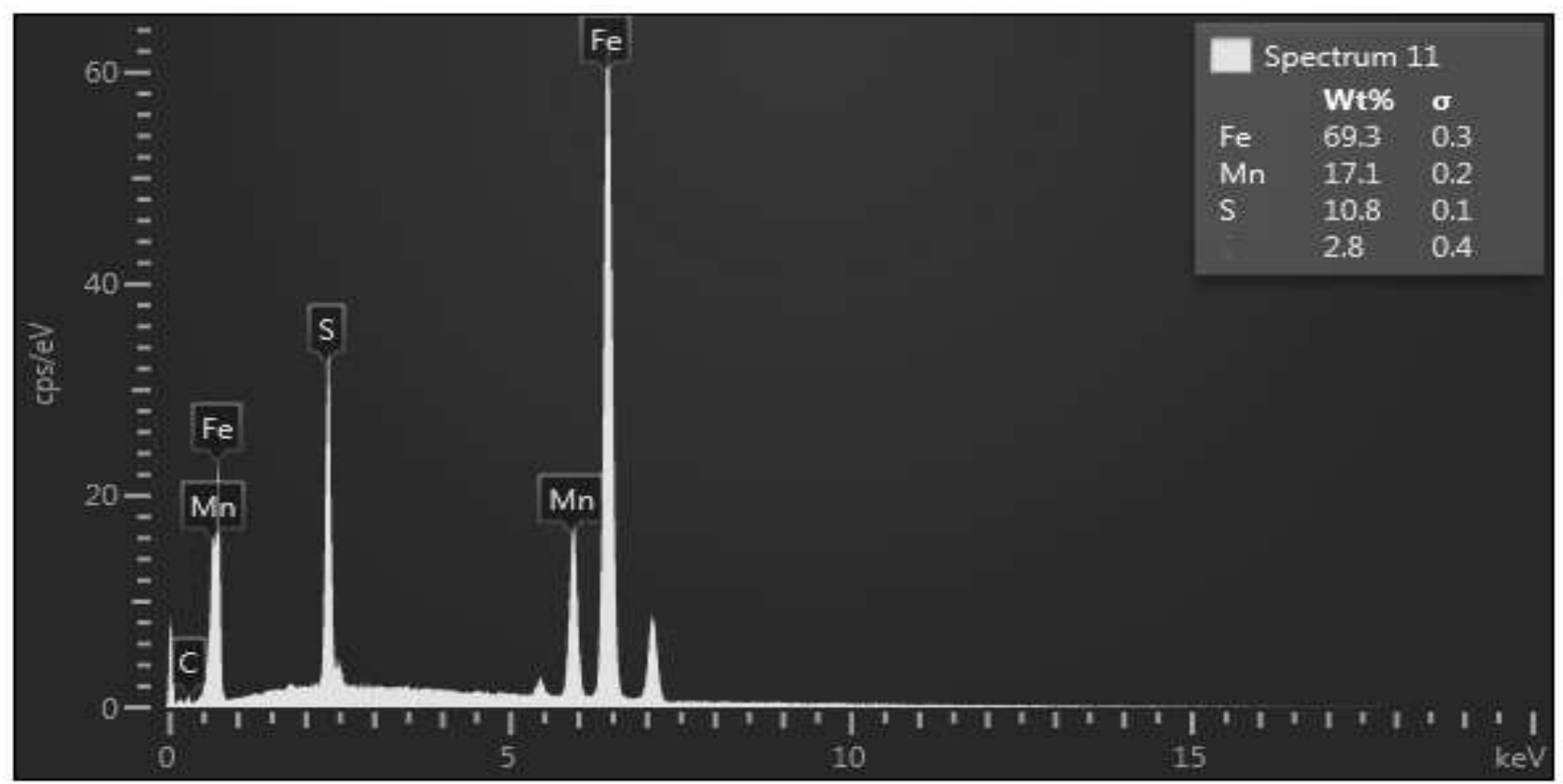

Fig. 8 Chemical spectrum 11 of $M n S$ inclusion

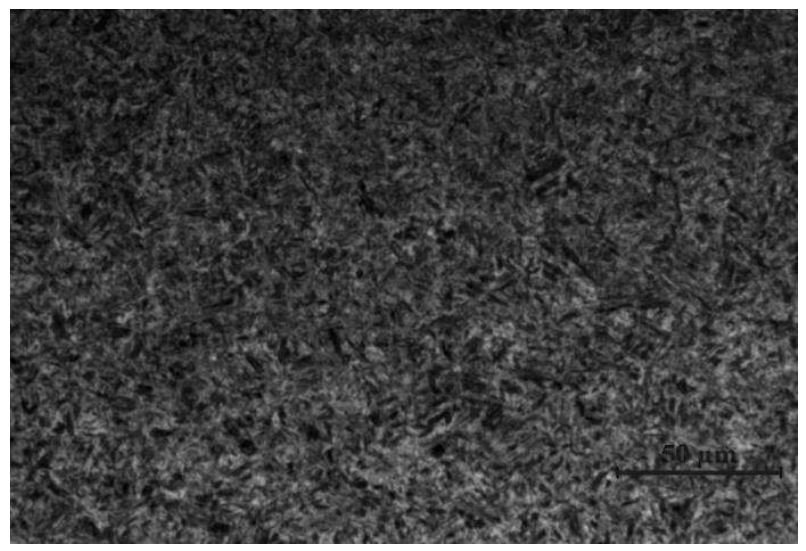

Fig. 9 Upper bainite structure of the matal core

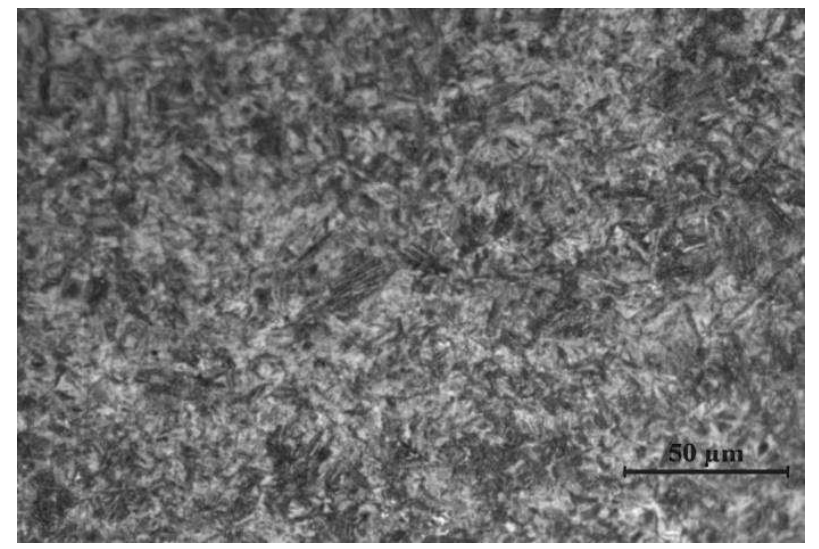

Fig. 10 Distribution of carbides in metal core

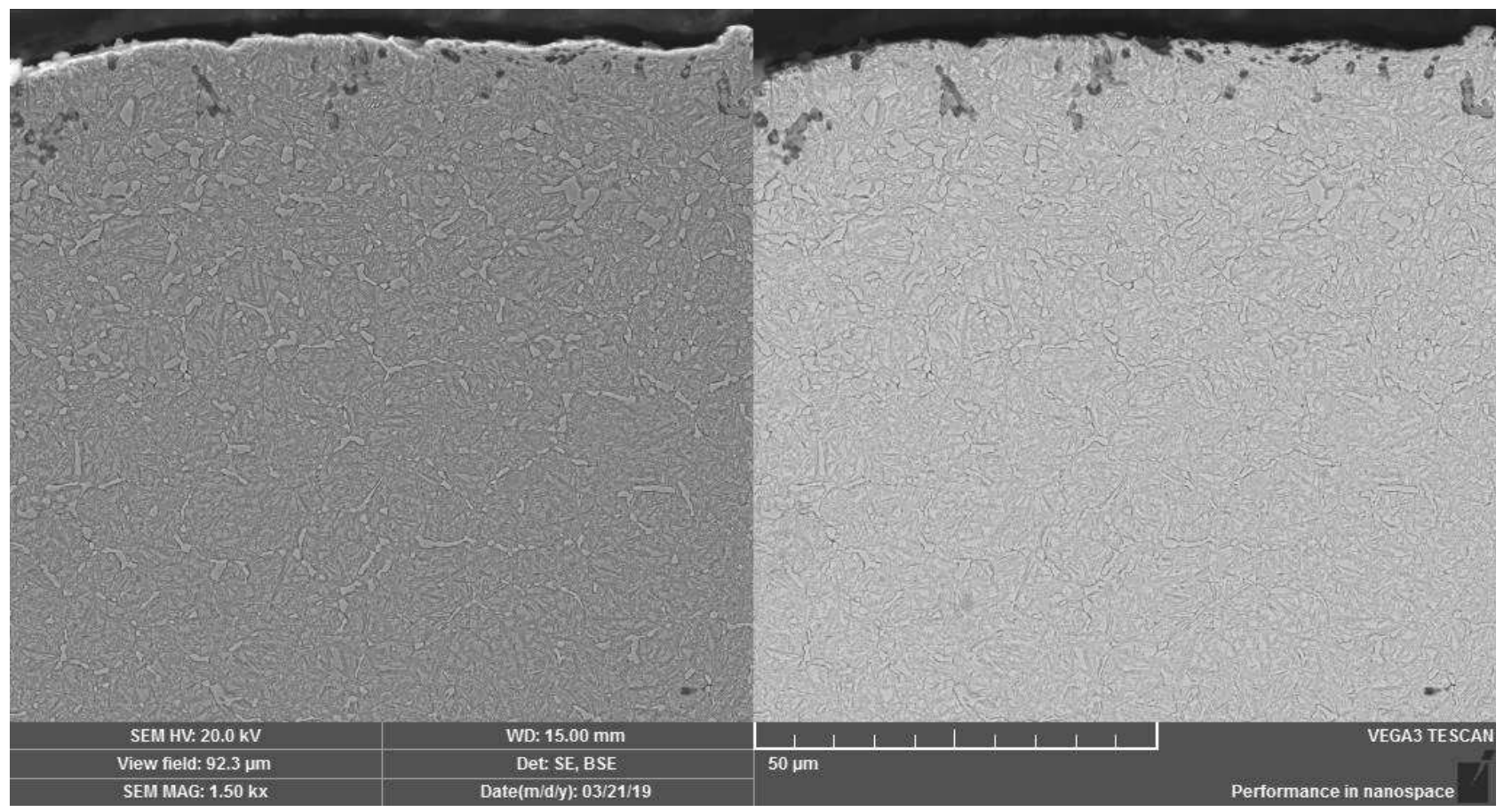

Fig. 11 Distribution of carbides close below the surface of gear tooth 
Tab. 1 The measured values of Vickers method

\begin{tabular}{|c|c|c|}
\hline Area & $\begin{array}{c}\text { Distance from the sur- } \\
\text { face }[\boldsymbol{\mu m}]\end{array}$ & $\begin{array}{c}\text { Hardness } \\
{[\mathbf{H V}]}\end{array}$ \\
\hline A & 47.347 & 733 \\
\hline B & 55.941 & 683 \\
\hline C & 209.546 & 774 \\
\hline D & 226.951 & 835 \\
\hline E & 346.777 & 671 \\
\hline F & 499.689 & 569 \\
\hline G & 609.913 & 543 \\
\hline H & 664.05 & 526 \\
\hline I & 882.878 & 511 \\
\hline J & 1085.62 & 503 \\
\hline
\end{tabular}

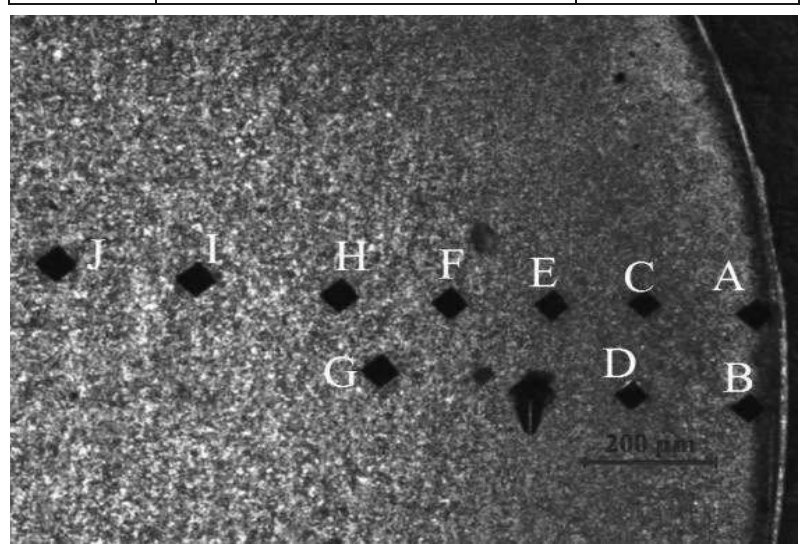

Fig. 12 The hardness measurement process

More of surface-initiated microcracks were observed on the heel area of the defective gear tooth, which distributed perpendicular to the core of the material. A representative crack from this area is shown in (Fig. 13). The cracks were analyzed on the backscattered electron mode, as the empty micro space created by the crack distribution creates a significant contrast in the analyzed area. This significant contrast is visible when using a BSE detector. The distribution of microcracks was visible up to a depth of $0.9 \mathrm{~mm}$. The cracks did not show an increased degree of branching. The microspace created by the decohesion of the material during crack propagation was filled by oxides and material from the preparation of the metallographic cut [6].

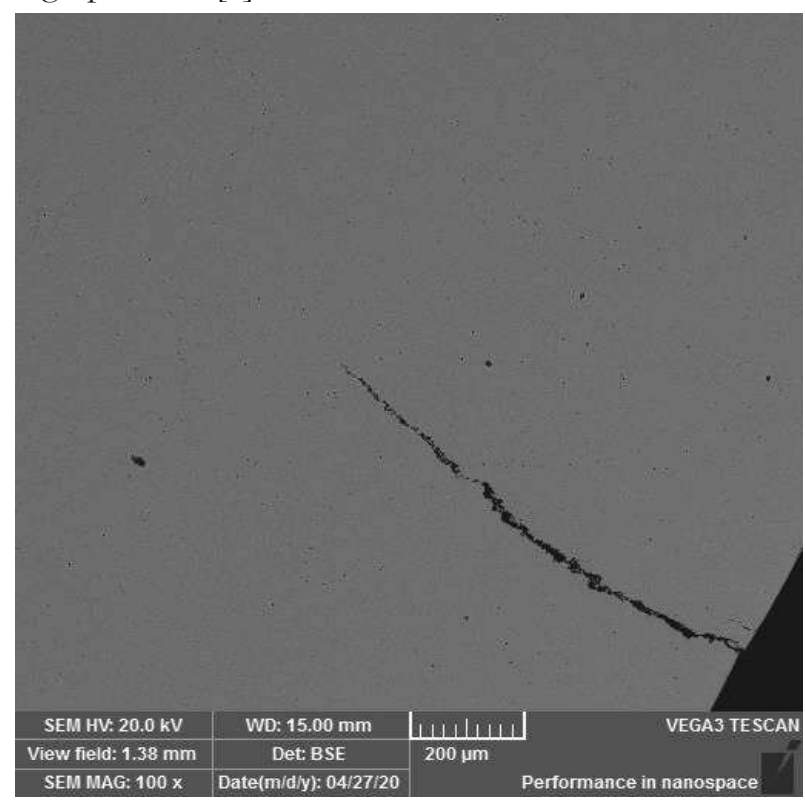

Fig. 13 Distribution of surface microcrack

In the analysis of microstructural changes in the surface area of microcrack propagation, the occurrence of inclusions distributed along the grain boundaries was observed. The analyzed inclusions were of the $\mathrm{MnS}$ type with longitudinal shape (Fig. 14). Due to their size and shape, they filled the entire area of individual sides of the polygonal grain shape in several places. The material contrast of these inclusions shows that they consisted of doped parts with manganese and contrariwise [7].

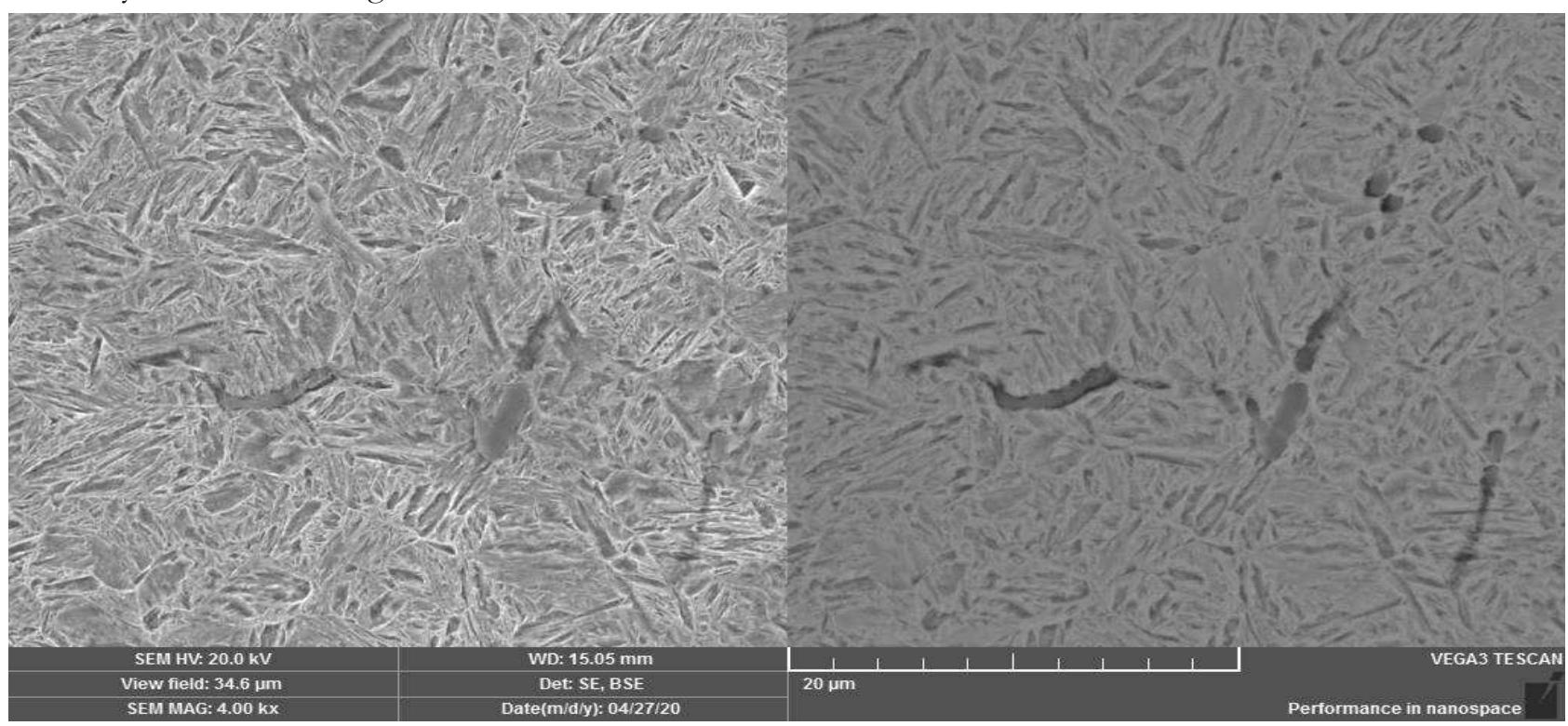

Fig. 14 Distribution of MnS inclusions along the grain boundaries 
Inclusions of smaller globular-shaped were also observed, which were distributed along the grain boundaries, thereby weakening them (Fig. 15, 16). The weakening of the grain boundaries is also confirmed by the absence of crack distribution towards the grain of the metal matrix. Near the metal matrix, the occurrence of secondary microcracks was observed locally, which increases the proportion of decohesion between the metal grains [8]. The crack space is filled by the crystalline phase, most likely the presence of oxides and elements that could be introduced into the microcrack space from the sample metallographic preparation process.

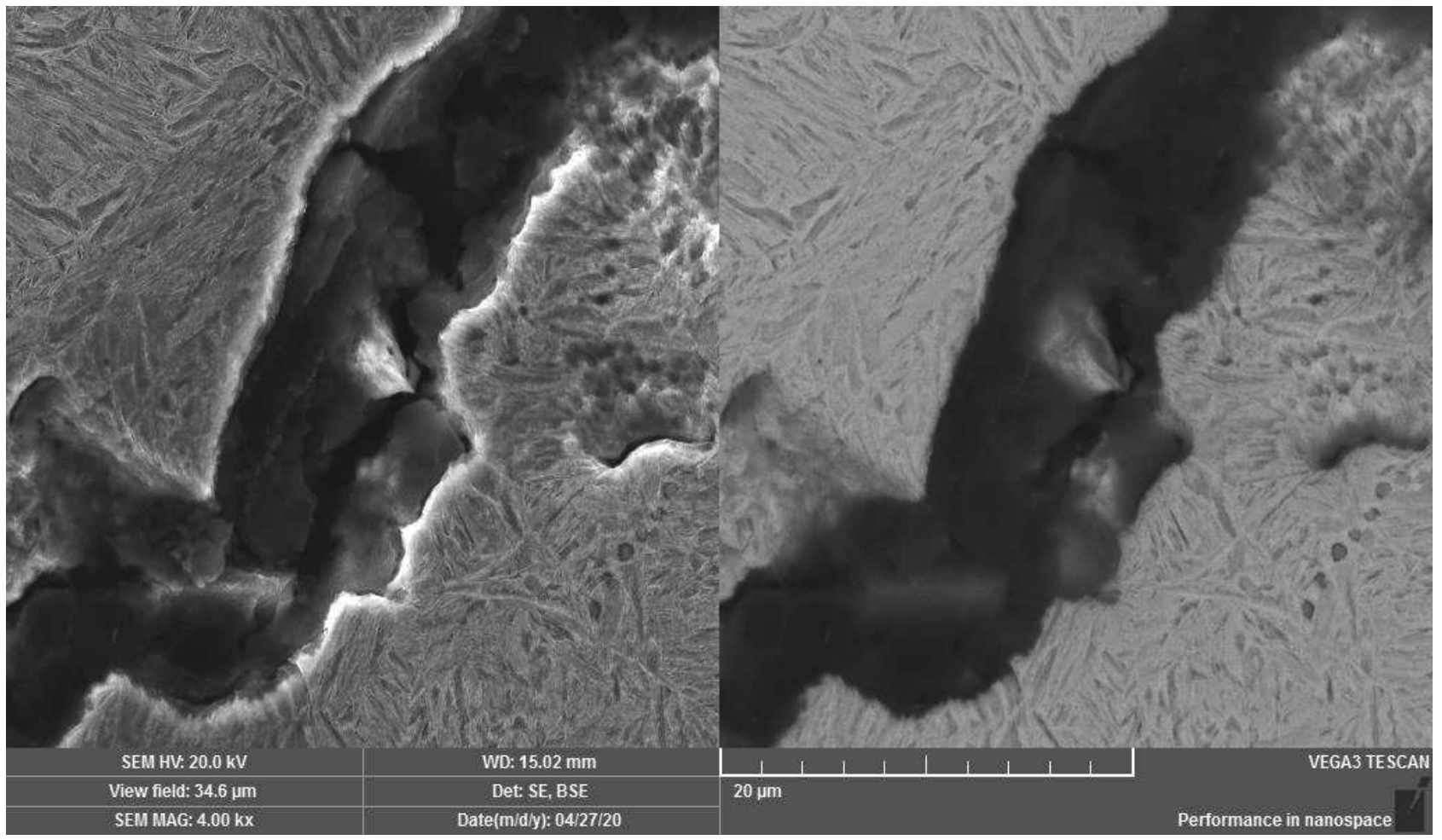

Fig. 15 Microspace of crack distribution with inclusions witch are formed along grain boundaries

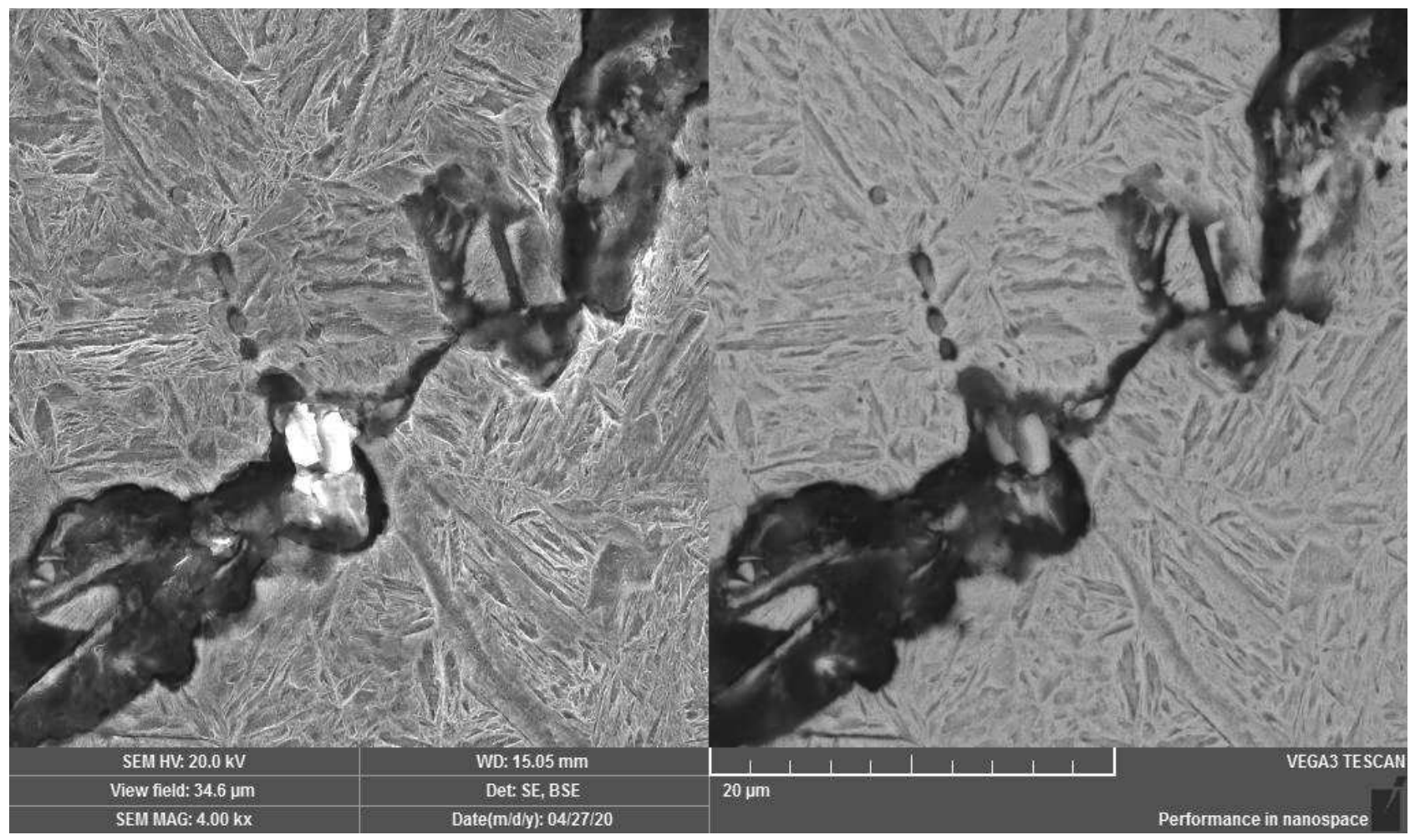

Fig. 16 Distribution of inclusions with globular shape 


\section{Conclusions}

Based on the information obtained from the analyzes performed, it is clear that the method of processing the gear wheel has been designed correctly. The processing of the part has been designed to achieve a high hardness on its surface, which prevents wear when in contact with the counterpart in the gear mechanism. The core of the part is tough and so there should be no crack propagation perpendicular to the material, as the crack must reach high energy values. Despite the application of chemical-thermal processing of the gear wheel, the wheel tooth was broken, which caused the entire transmission mechanism to malfunction. Analysis of the microstructure of the core by optical microscopy gives us information about the correct setting of the thermal regime, as the grain size of the metal matrix is optimal and inclusions in the microstructure are absent to such an extent that it could cause the propagation of microcracks. During the analysis of the surface of the components, the distribution of carbides along the grain boundaries was visible and also inclusions were observed to a greater extent along the grain boundaries. This condition could be caused by the increased carbon content in the cemented layer and thus its toughness decreased. Another factor that led to the formation of a large number of surface microcracks could be the increased chromium content in the material. Chromium is carbideforming elements, resp. this element increases the carbon content on the surface of the cemented layer. For this type of material, it would be suitable for the formation of the cementation layer to take place in a less active environment. According to the manufacturer of this transmission spare part, the gear was made of steel grade 14 (EN ISO 20MnCr5). This material is suitable for the production of this type of components while maintaining optimal material properties in the production of gears up to a diameter of $40 \mathrm{~mm}$. The gear had a diameter of $74.4 \mathrm{~mm}$, which means that a larger volume of material could also affect the optimal chemical heat treatment. In order to prevent the fracture of this type of component in the future, the manufacturer must pay attention to the correct process of carburization of the gear surface, the chromium content in the material, and especially to adhere to a suitably selected chemical thermal regime of component processing.

\section{Aknowledgement}

The contribution was supported by the Slovak grant project No. KEGA 002TnUAD-4/2019. The work was supported by the project, Advancement and support of R\&D for "Centre for diagnostics and quality testing of materials" in the domains of the RIS3 SK specialization", code NFP313011W442.

\section{References}

[1] VLK, F. (2005) Motorcycle transmission, Forensic Engineering, no. 2, Institute of forensic engineering Brno University of Technology, Brno, pp 109 - 123.

[2] MORAVCIK, R., HAZLINGER, M., HUDAKOVA, M., MARTINKOVIC, M., CICKA, R. (2010). Materials Science 1, AlumniPress, Trnava, 249 p.

[3] BAKSA, T., ADAMEK, P., HRONEK, O., ZETEK, M. (2019). Degradation of a Grinding Wheel when Grinding Cermet Materials and Its Influence on the Grinding Process. Manufacturing Technology 19, no. 1, pp $9-13$

[4] SAPIETA, M., SULKA, P., SVOBODA, M. (2018). Monitoring the fatique crack on the test specimen during the cyclic loading. In: MATEC Web of Conferences 18, no. 157

[5] BUNDA, Z., KUCEROVA, L., KEPKA, M. (2019). The Crack Analysis of Fatigue Tested Steel Construction. Manufacturing Technology 19, no. 19, pp 559 - 62

[6] BAKSA, T., FARSKY, J., HRONEK, O., ZETEK, M. (2018). Impact of Cutting Speed on Grinding Wheel Wear and Cutting Force when Grinding Cermet. Manufacturing Technology 18, no. 8, pp $699-703$

[7] PTAČEK, L., et al, (2002). Material Science II, Academic Publishing CERM, Brno, 392 p.

[8] MURAKAMI, Y. (2002). Metal Fatigue, Effect of small defects and nonmetallic inclusions. Elsevier publ., Oxford, UK. 